\title{
Joint statement on the provision of a dental prophylaxis under COVID-19 alert status
}

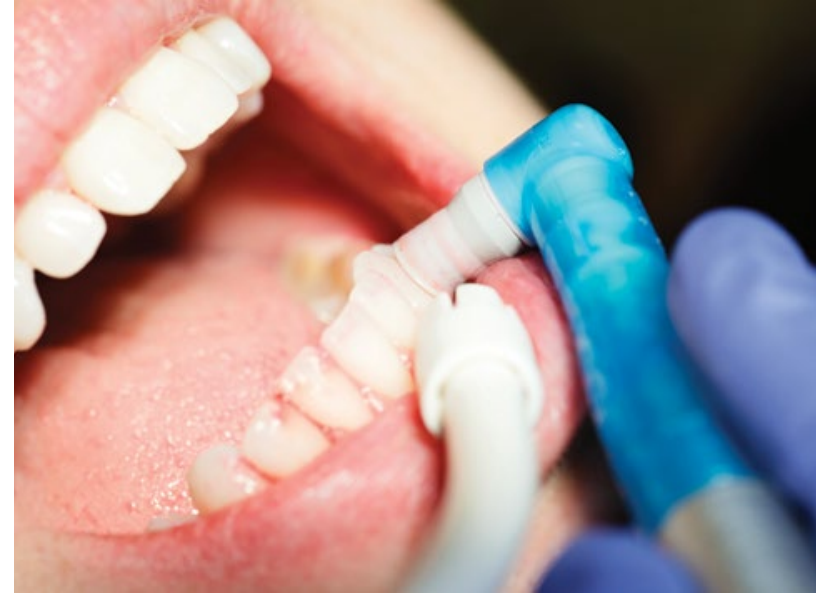

The British Society of Periodontology and Implant Dentistry (BSP), the Faculty of General Dental Practice (UK) (FGDP[UK]) and College of General Dentistry (CGDent), working with the Office of the Chief Dental Officer for England, have issued a joint statement to clarify and contextualise the differences in guidance issued relating to the provision of a dental prophylaxis under Level 4/3 COVID-19 alert status.

The BSP guidance relates to prophylaxis as part of professional mechanical plaque removal (PMPR) in people with periodontitis. The FGDP(UK) guidance in periodontitis patients if this is withheld.

A prophylaxis undertaken with a slow speed handpiece, with no water, reduced prophy paste and due diligence, is considered a non-aerosol generating procedure (nonAGP) as defined by emergent particle sizes (WHO 2007) and can be safely undertaken with level 2 PPE (R11 mask, gloves, goggles/ visor, plastic apron over scrubs). However, non-AGP procedures are not without some risk and polishing teeth for cosmetic reasons is not recommended until Level 2 alert status is reached. Prophylaxis does cause splatter which can travel in a ballistic manner between $15-120 \mathrm{~cm}$ from patients' mouths and which may contact the eyes, mouth and skin of the operator/assistant; hence the need for level 2 PPE. Teeth should be dried with gauze and high volume aspiration is recommended.

The BSP guidance provides a risk categorisation based on procedure. The FGDP-CGDent guidance adopts a similar approach but uses the terms low and highrisk aerosol generated exposure (AGE), to ensure additional factors are taken into consideration when considering exposure to risk. These include length of procedural exposure to splatter, risk of exposure to naturally-generated aerosol (coughing, sneezing or breathing), and the potential to apply mitigation measures. These are different approaches and both have value and require professional judgement by clinicians on a case-by-case basis, whilst accounting for the COVID-19 risk of the operator and assistant.

For further information see https:// www.fgdp.org.uk/implications-covid19-safe-management-general-dentalpractice-practical-guide and https:// www.bsperio.org.uk/publications/ downloads/126_122551_bsp-back-to-workversion-2---risks-associated-with-steps-oftreatment-0706-2020.pdf.

\section{BES announce new COVID-19 research grant}

The British Endodontic Society (BES) has announced a new research grant of up to $£ 40,000$ in response to the COVID19 pandemic. The Society is inviting proposals from UK-based applicants wishing to undertake short-term research that addresses or mitigates the impacts of aerosol generating procedures (AGPs) during the COVID-19 outbreak.

Dr Sanjeev Bhanderi, BES President (pictured), said: 'The impact of COVID-19 on dentistry has been significant and as we begin to return to the "new normal", we face a complex and evolving situation. There is an abundance of guidance available, but a common theme is the lack of robust evidence to guide the adoption of behaviours in practice. Many questions surround AGPs in dental practice and the interaction of these with COVID-19 so the BES is investing in research that will lead to a better understanding?.

Applicants do not need to be BES members and the closing date for submissions is 15 July 2020. The application process is outlined on the BES website and all applications will be considered by the BES research panel appointed by the BES Council. Due to the immediacy of this research, the successful applicant will be notified by 31 July 2020 .

For further information visit: https:// britishendodonticsociety.org.uk/profession/ grants/call-for-research-to-address-theimpact-of-aerosol-generating-proceduresin-dentistry-with-respect-to-covid-19/.

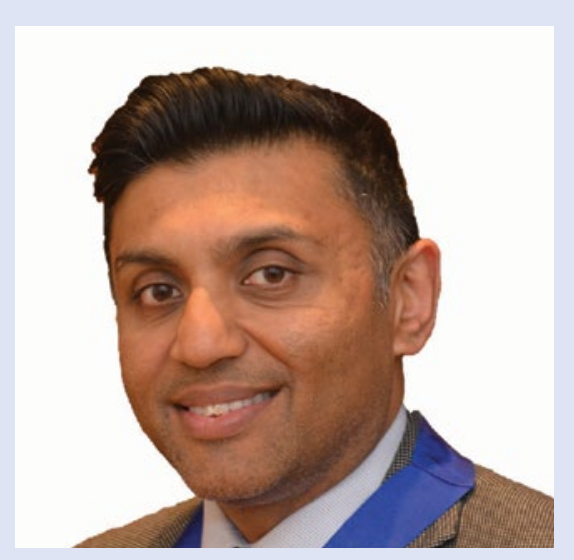

